\title{
Reaproveitamento da casca de coco verde
}

\author{
Reclamation of the coconut shell \\ Alessandro Costa da Silva' \\ 'Universidade Estadual do Maranhão
}

\section{Resumo}

A grande geração de resíduo proveniente do uso cotidiano de coco verde (Coccus nucifera L.), necessita de estratégias para evitar poluição visual e contaminações. Devido a seu peso e volume quando descartado, seja na forma oca (fechado, sem água) ou na forma de casca (aberta em bandas), diminui o tempo de vida dos aterros e lixões. Uma possibilidade seria o reaproveitamento da casca (mesocarpo fibroso) como produto artesanal, industrial ou insumo agrícola. Algumas classes de solos do Brasil necessitam de insumos como prática de manejo, e o uso da casca (fibra) é uma possibilidade. Embora o teor de lignina e celulose dificultem a degradabilidade dessa fibra no solo, ainda assim pode ser incorporada, consorciado com outros substratos, para fornecimento de nutrientes e melhora dos parâmetros físicos. $\mathrm{O}$ aproveitamento deste resíduo em projetos de agricultura familiar pode estimular a inclusão social, além de gerar trabalho e renda, principalmente nas cidades praianas.

Palavras-chave: Fibra de coco. Resíduo. Sustentabilidade.

\begin{abstract}
The great and daily generation of waste from use of coconut (Coccus nucifera L.), requires strategies to prevent visual pollution and contamination. Due to the weight and volume when discarded is in hollow form (closed, no water) or in the form of coconut shell (open in bands), decreases the lifetime of landfills and dumps. One possibility would be the reclamation of shell (mesocarp fiber) like a handmade and industrial products or agricultural input. Some classes of Brazilian soils need a way of management. Although the lignin and cellulose hinder the degradability of fiber in soil still is indicated for nutrient supply in associated with other substrates and can also be incorporated for lowlands improving its physical parameters. The use of this coconut residual in agriculture family projects can stimulate social inclusion, besides generating employment and income, especially in beach cities.
\end{abstract}

Keywords: Coconut fiber. Waste. Sustainability. 


\section{INTRODUÇÃO}

De acordo com dados do Ministério das Cidades poucas cidades (cerca de 35\%) cumpriram a lei de resíduos sólidos, que passou a vigorar em 04 de agosto de 2014. A lei obriga todos municípios brasileiros a darem o descarte adequado para o lixo (doméstico, industrial e hospitalar) reduzindo, reutilizando e/ou reciclando-o; sendo sua escória (rejeito) disposto de forma adequada locais específicos (BARBOSA, 2014).

Cabe lembrar que nesses resíduos incluem-se também os de origem agrícola; aqueles gerados como subprodutos do beneficiamento de grãos, laticínios, pecuária e da hortifruticultura. Entre os principais, tem-se aqueles provenientes das cascas de coco, pinheiro, trigo, arroz, milho, sorgo, cevada, cana-de-açúcar, banana e de cítricos (ROSA et al., 2002). Embora a maioria desses resíduos causem transtornos no ambiente rural, alguns como o caso do coco verde (Coccus nucifera L.) causam no ambiente urbano, principalmente das cidades praianas.

O coco verde apresenta facilidade para comercialização, pelo baixo custo e disponibilidade; por isso a presença de muitos vendedores ambulantes em áreas de lazer e recreação. Mas o aumento do consumo aumenta também a possibilidade de impacto ambiental nessas áreas. O acúmulo dos cocos descartados, acrescido do fato de não poderem ter seu volume reduzido (por causa da dureza), trazem dificuldades logísticas e ambientais. Mesmo quando transportado para locais de disposição, por causa de seu longo tempo de decomposição, diminuem o tempo de vida útil dos lixões e dos aterros sanitários.

Dados da Embrapa Tabuleiros Costeiros revelam que, a cada 125 cocos descartados, após consumo de sua água, estes vão ocupar $1 \mathrm{~m}^{3}$ de espaço nos aterros (CINTRA et al., 2009). Cabe lembrar que, diferente do lixo comum presentes nas praias, esses cocos, por causa de seu peso e volume, não podem ser recolhidos manualmente durante campanhas de educação ambiental. Além de danificarem os recipiente de coleta de lixo, que em geral são de plástico e acabam quebrando.

Pesquisadores como Martins e Jesus Jr (2010) estimam que sejam descartados no Brasil cerca de 7 milhões de toneladas de coco por ano. Esses cocos, que poderiam ser aproveitadas para gerar uma série de produtos, acabam sendo acumulados criando incômodos para a população. Um demorado incômodo pois o tempo médio de decomposição desses resíduos (cocos descartados), provenientes do pós-consumo, é de longos 12 anos.

A questão do acúmulo dos cocos descartados ainda é um gargalo a ser resolvido, que evitaria poluição visual e contaminação. Esse resíduo pode ser matéria-prima na fabricação de diversos produtos industriais e artesanais criando trabalho e renda, ou ainda usado como insumo agrícola e até biomassa, gerando energia. Nesse sentido, serão apresentadas algumas agregações de valor por meio da trituração da casca do coco para retirada de sua fibra visando reaproveitamento.

\section{METODOLOGIA}

O presente artigo foi elaborado na forma de uma revisão bibliográfica e, para isto utilizou-se procedimentos de levantamento e consulta em literatura especializada. A proposta tem um caráter informativo e pretende proporcionar ao leitor uma visão geral do assunto abordado: suas contradições, aplicações e possibilidades.

\section{RESULTADOS E DISCUSSÃO}

\subsection{O coqueiro: produção e consumo}

Entre as palmeiras tropicais, uma das mais difundidas em todos os continentes é o coqueiro (Cocos nucifera L.), originária da Índia e pertencente à família Palmae, uma das mais importantes famílias da classe Monocotyledoneae (GOMES, 2003). O coqueiro chegou ao Brasil, vindo de Cabo Verde, em meados de 1950 chegando ao Estado da Bahia, por isso algumas vezes é chamado de coco-da-baía. Depois foi disseminado pelo litoral nordestino, especialmente por ser uma frutífera típica de clima tropical onde encontrou condições favoráveis para cultivo e, posteriormente acabou se adaptando em outras regiões do país (CINTRA et al., 2009). 
O fruto do coqueiro (o coco) é uma drupa, formada por uma epiderme lisa ou epicarpo, que envolve o mesocarpo espesso e fibroso, ficando mais no interior uma camada muito dura (pétrea), o endossarão. Este fruto fica envolto numa casca externa esverdeada ou amarelada, que com o tempo, torna-se seca e amarronzada (FERREIRAet al., 1998). Sob a casca do coco encontra-se uma camada de 3 a $5 \mathrm{~cm}$ de espessura, o mesocarpo. Situado entre o epicarpo e o endocarpo, é constituído por uma fração de fibras curtas e longas e outra fração denominada pó, que se apresenta agregada às fibras (ROSA et al., 2001).

O coco tem estrutura formada por um interior oco, onde se encontra o albúmen líquido (água), que vai progressivamente se transformando em albúmen sólido. Este é envolvido por uma sapucaia, o endocarpo (parte mais dura), a que se sucede o mesocarpo (casca) que constitui a maior parte do fruto, e finalmente um fino exocarpo, geralmente de cor verde, amarela ou marron (ARAGÃO, 2002).

O Brasil possui cerca de 290 mil hectares cultivados com coqueiro, distribuídos em quase todo o território nacional com produção equivalente a dois bilhões de frutos/ano. Entre 1990 a 2009 passou do décimo ao quarto maior produtor mundial, e as perspectivas de crescimento aumentam, tanto na produtividade quanto na abrangência do mercado (FAO, 2014).

Mesmo havendo incremento na área colhida desde 1990, ainda assim o que se verifica, é um aumento vertiginoso na sua produtividade principalmente na faixa litorânea do Nordeste e parte da região Norte, que devido suas condições climáticas, concentram cerca de $70 \%$ da produção brasileira (MARTINS e JESUS Jr., 2011).

A estrutura do mesocarpo, por ser mais abundante em fibras, apresenta uma elevada relação $\mathrm{C} / \mathrm{N}$, na faixa de 130 a 135 , esta propriedade contribui para um alto tempo de decomposição natural, entre 10 e 12 anos (CARRIJO et al., 2002). O que lhe confere, portanto, diversas aplicações: na produção de utensílios estruturais como vasos, mobiliários, cascos de embarcações, carga para concretação, entre outros (SANTIAGO e SEVAN, 2007) ou na forma de matéria-prima como agregados para a indústria química, farmacêutica e alimentícia ou para uso como substrato para a agricultura (Van DAM et al., 2004).

O potencial de mercado é bastante promissor, competindo inclusive com as bebidas do tipo isotônicos, por suas propriedades funcionais. Mas para isso torna-se necessário o desenvolvimento tecnológico de processamento e embalagens que permitam manutenção das características nutricionais e o sabor da água-de-coco (CARVALHO et al., 2006).

De acordo com Holanda et al. (2007), esse cenário produtivo coloca o Brasil como líder mundial na produção de coco verde, que são capazes de armazenar em média $300 \mathrm{~mL}$ de água. A possibilidade de aumento de consumo, aliado ao crescimento populacional e a preocupação com a saúde, demonstram claramente a potencialidade deste setor perante a cadeia produtiva de coco. Martins e Jesus Jr. (2011) comentam que a região Nordeste representa $83 \%$ do total da área plantada de coco e, $70 \%$ do valor total do coco produzido do Brasil.

Em muitos países o coqueiro é conhecido como árvore de vida, devido seus usos múltiplos, como o tronco, que novo pode ser usado para construir casas e quando velho serve como substrato para mudas. As folhas quando novas servem para confeccionar produtos trançados, e quando adultas, para cobrir cabanas e confeccionar chapéus; as flores que produzem açúcar, a semente que é comestível e pode ser usada na forma de doces e salgados e até as raízes podem ser aproveitadas. É, as raízes novas funcionam como complemento nutricional, servirem como fortificantes das gengivas e serem eficazes, na forma de chá, contra diarréias.

Além dessas possibilidades, existe ainda a utilização, também, de todas as partes de seu fruto: o próprio coco. A água nutricional, excelente repositor de potássio e isotônico, combate a icterícia, as irritações no estômago e intestino, inflamações nos olhos, vômito durante a gravidez e é também um ótimo diurético (MATHAI, 2005). O autor ainda sugere que o coqueiro é uma excelente cultura que serve como alternativa para reflorestamento de áreas degradadas, além de ser uma palmeira de grande beleza ornamental, sendo o clima do Brasil em geral favorável ao seu desenvolvimento.

Mesmo após consumida a água e o albúmen a casca do coco descartada pode ser aproveitadas como fonte de energia, sendo queimada para a produção de carvão, carvão desodorizante e carvão ativado. Podendo extrair suas fibras que servem na fabricação de uma diversidade riquíssima de artigos como vestuário, tapetes, sacaria, almofadas, colchões, acolchoados para a indústria automobilística, escovas, pincéis, capachos, passadeiras, tapetes, cordas marítimas, cortiça isolante, cama de animais 
(MARTINS et al., 2013). O pó resultante da extração das fibras pode ser usado para fabricação de linhas para pescaria, solados de sapatos, cascos de barcos, ou podem ainda ser queimados e retornar ao coqueiral em forma de cinzas (Van DAM et al., 2004).

Cabe lembrar, que (como ocorre com o peixe) o consumo de água de coco no interior do Brasil ainda é pequeno, concentrando-se no litoral. De acordo com associação das indústrias de refrigerantes e de bebidas não alcoólicas (ABIR, 2011), apenas 1,4\% do consumo no mercado de refrigerantes e bebidas é devido ao consumo de água de coco. O movimento de água de coco no Brasil em 2008 foi de cerca de 60 milhões de litros, tendo um consumo per capita anual de $310 \mathrm{~mL}$, e esse baixo consumo só demonstra o forte potencial, cujo segmento cresceu a uma taxa (14\%) superior em relação aos $9 \%$ relativos a mercado de sucos prontos.

Diferente de muitas outras culturas temporárias, a comercialização do coco no Brasil pode ser realizada durante ano todo, com a capacidade de propiciar ao produtor, um fluxo contínuo de receita ao longo da vida produtiva do coqueiro. O mercado do coco no Brasil tem crescido nos últimos anos, não só pelo aumento de áreas de plantios, mas pelo crescimento do consumo da água na região central do país. Possivelmente impulsionados pela inclusão de hábitos saudáveis no comportamento da população brasileira (REBELLO et al., 2000).

De acordo com Cunha (2011), estima-se, que o coco vendido de maneira informal, responda por $80 \%$ do volume consumido de água de coco em todo território brasileiro. Já o consumo da água de coco por áreas específicas como medicina, biotecnologia, nutrição, entre outras, está na faixa de 100 a 350 milhões de litros por ano, com uma taxa de crescimento de, aproximadamente, $20 \%$. Como exemplo desse consumo pela população em geral, empresas como a Ducoco lançou um suco de fruta diluído em água de coco, e a PepsiCo investiu fortemente em água de coco envasada por meio da marca KeroCoco. Ainda existem centenas de empresas que comercializam água de coco envasada em quase todos os supermercados espalhados pelo país.

Embora exista uma gama de possibilidades na vasta cadeia produtiva do coco ainda assim seu resíduo, coco descartado após consumo, é deixado de lado como um lixo comum. E, mesmo sabendo que, também existe uma gama de possibilidades no reaproveitamento desse resíduo (lixo), os gestores e a sociedade (em geral) o descarta como sendo um problema ambiental.

É bom ressaltar que a palavra "problema" deveria ter aplicação somente nos processos humanos, pois o enfrentam em sua existência e realizam escolhas permitindo agir. Para Samaja (2000), uma atividade fundamentada sobre a noção de "problema" deveria, para ser completa, apresentar uma solução. A ausência de respostas para o "problema" por parte do comerciante e do governo, distancia os consumidores sobre os benefícios dessa logística reversa.

\subsection{Coco descartado: possibilidades de reaproveitamento}

Como sabido, o consumo de coco em ambiente urbano gera uma quantidade elevada de resíduo, seja em volume seja em peso, podendo provocar desconfortos no sistema de gestão sanitária das cidades (SENHORAS, 2004). Mesmo com recipientes de coleta é comum o transbordamento dos cocos descartados podendo causar a contenção do fluxo hídrico, com entupimento de córregos, bueiros e vias públicas. Nos ambientes tropicais como no nordeste brasileiro, constitui uma condição favorável para proliferação de vetores para doenças de ampla veiculação, sendo considerado, em alguns casos, como questão de saúde pública.

De acordo com Rosa et al. (2002), doenças como dengue podem proliferar tanto quando o coco é descartado fechado apenas a com um perfuração (feita para a retirada da água), quando é descartado aberto na forma de duas bandas, depois de extraído o albúmen sólido, em ambos os casos ocorre acumulo de água de chuva, podendo ser um depositório de mosquitos. Daí reside a necessidade de pesquisas e estudos para evitar o acúmulo desse resíduo, agregando valor e inserindo populações excluídas nesse processo.

O coco, seja verde ou seco, apresenta uma casca que guando descartada pode chegar a compor cerca de $85 \%$ do peso bruto do resíduo, isto é, do próprio coco. Por ser um material ecológico, esse resíduo pode ser reaproveitado na fabricação de vários produtos. A reutilização e a reciclagem do coco tem sido proposta como forma de amenizar os impactos ambientais causados pela quantidade exagerada no seu descarte. O reaproveitamento de sua casca poderia minimizar desconfortos na sua disposição em lixões e incluir populações nessa nova cadeia produtiva (CORREIA et al., 2003; APA- 
OLAZA et al., 2005).

Esses fatores demandam um grande custo financeiro para sua mitigação e indicam necessidade de pesquisas visando estratégias para melhor aproveitamento do coco descartado (REDDY e YANG, 2005). O desenvolvimento de alternativas de reaproveitamento desse resíduo nas suas mais variadas possibilidades (artesanato, engenharia, farmacêutica, agronômica, etc.), deve ser pensada pela sociedade e pelos gestores das cidades, visando a sustentabilidade.

O reaproveitamento do coco descartado (resíduo), por meio de sua trituração para obtenção de fibra e pó, ainda é considerada como forma para agregação de valor ao resíduo, principalmente quando incorporado ao solo. Segundo Carrijo, et al., (2002), tanto a fibra quanto o pó de coco é um excelente material orgânico, devido às propriedades de retenção de água, aeração do meio de cultivo e estimulador de enraizamento. A facilidade de produção, baixo custo e alta disponibilidade são outras vantagens adicionais apresentadas por estes materiais.

Pertencente à família das fibras duras, as fibras extraídas do mesocarpo do coco é classificada como lignocelulósicas, compostas principalmente por lignina e celulose que the conferem elevados índices de rigidez (MATHAI, 2005). Essa fibra que encontra-se no mesocarpo, região mais volumosa do fruto, está sendo estudada visando seu reaproveitamento (FLORENTINO et al., 2011).

A fibra, bem como seu pó, é obtida por meio da dilaceração, moagem e secagem do seu volumoso e fibroso mesocarpo. Segundo Corradini et al. (2009), a fibra do coco verde por ser constituído de carboidratos como lignina e celulose, podem ser utilizadas na obtenção de açúcares fermentáveis (monossacarídeos) para a preparação de etanol lignocelulósico.

A fibra extraída de coco seco (frutos de 2 a 3 anos) vem sendo utilizada preferencialmente na indústria, que após processada origina vários sub-produtos. No Brasil, a fibra desse coco foi muito utilizada na fabricação de estofados de automóveis desde a década de 1970, mas perdeu espaço para o poliuretano nos anos de 1990 (SANTOS, 2006).

Já a fibra extraída do coco verde (frutos de 7 e 8 meses de idade) é a mais aproveitada por causa do grande volume produzido diante ao consumo de água de coco. Sendo muito usada em paisagismos e jardinagem pela excepcional adaptação na forma de vasos em substituição ao xaxim e por sua alta porosidade, facilitando o enraizamento e por ser anti-fungo (ARAGÃO, 2002). Outras aplicações encontram nos setores moveleiro, têxtil, calçadista, design de objetos para o lar, compósitos, papeleira e embalagens, construção civil, filtros e mantas industriais.

Pesquisadores como Satiro et al. (2012) estudou a possibilidade de usar a fibra da casca do coco verde como matéria-prima para a obtenção de etanol lignocelulósico, através da deslignificação das fibras e obtenção de açúcares fermentáveis. Gerando uma outra cadeia de possibilidades de reaproveitamento da casca do coco: a bioenergia. Cabe lembrar que em países como a Índia é possível encontrar uma imensa variedade de produtos advindos do processamento da casca do coco triturada, seja a partir de sua fibra ou de seu pó (MATHAI, 2005)

\subsection{Experiências agronômicas}

Poucos estudos têm sido realizados visando a utilização potencial da casca de coco na agricultura de campo, a maioria são experimentos realizados em casas de vegetação. Uma possível explicação pode ser o fato de alguns pesquisadores acreditarem que esse subproduto poderia inibir o crescimento de alguns vegetais, causando prejuízos. Pedra et al., (2006) ressaltam que a casca de coco (mesocarpo) é um resíduo que apresenta elevada concentração de tanino, composto tóxico responsável pela possível redução do crescimento de algumas plantas.

Alguns estudos foram realizados para verificar a potencialidade do uso da casca do coco como insumo na agricultura. De acordo com pesquisadores, a composição elementar $\left(\mathrm{g} \cdot \mathrm{kg}^{-1}\right)$ do mesocarpo do coco é: Nitrogênio 2,38; Fósforo 1,14; Potássio 9,25; Cálcio 7,2; Magnésio 0,99; Sódio 11,12;

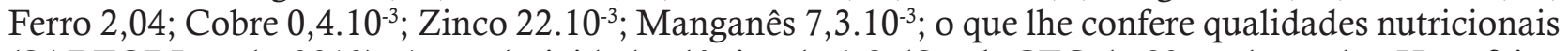
(SARTORI et al., 2012). A condutividade elétrica de 1,8 dS m $\mathrm{d}^{-1}$; CTC de 92; valores de $\mathrm{pH}$ na faixa de 5,5 e água facilmente assimilável de 19,8\%; lhe conferem qualidades físico-químicas. Já as altas porcentagens de lignina ( 35 a $45 \%$ ) e celulose ( 23 a $43 \%$ ) lhe conferem durabilidade (CARRIJO et al., 2002). O mesocarpo também apresenta qualidades físicas, sua capacidade de aeração é de $45,5 \%$ e sua densidade, tanto na forma de fibra quanto de pó, é de 0,22 e de $0,18 \mathrm{~g} \cdot \mathrm{mL}^{-1}$, respectivamente (BRIGIDA et al., 2010). Maiores informações sobre análises físico-químicas, físicas e químicas podem ser obtidas 
em trabalhos como os de Mattos et al. (2014).

Cabe aqui ressaltar, que a composição elementar da casca do coco descartado, bem como das propriedades (físicas, químicas e biológicas) de seu mesocarpo, dependerão das características e composição do solo onde o coco foi produzido, a época do ano e a quantidade de chuvas.

Pesquisas feitas por Apaolaza et al. (2005) revelaram que um substrato feito de fibra de coco apresenta um bom teor de matéria orgânica em torno de $80 \%$, mas com baixo grau de degradabilidade natural (alta relação $\mathrm{C} / \mathrm{N}$ ), e uma elevada salinidade. Esta última característica, que poderia ser prejudicial, não afetou o crescimento de coníferas. Explicado, provavelmente pelo efeito de solubilização dos sais pelas regas, durante a estação de crescimento, e um possível efeito tampão da matéria orgânica abundante.

Para evitar inconvenientes com salinidade, Matias et al. (2007), sugerem a retirada de sais antes de iniciar o experimento. Os pesquisadores comentam que o uso da fibra não lavada pode, além de retardar a germinação, proporcionar um crescimento menor de mudas, principalmente naquelas mais sensíveis ao sódio.

Para o uso de mesocarpo em experimentos, Carrijo et al. (2002) sugere que as cascas dos cocos de mesma origem, sem deformações ou doenças visíveis devem ser picadas com facão e trituradas em forrageiras com peneira de 3 ou $4 \mathrm{~mm}$, sendo lavadas em água de boa qualidade e armazenadas em local limpo e higienizado. O material deve ser compostado por 90 dias e enriquecido com nutrientes, sendo então usado em canteiros para hortaliças ou produção de flores em vasos.

A picagem manual, segundo Silva e França (2013), limita a produção e pode ser substituída por equipamentos desenvolvidos para esta finalidade. Um exemplo é o caso da empresa Jumil, que já comercializa uma trituradora para retirada do mesocarpo do coco, obtendo suas fibras. O maquinário é composto por 4 facas rotativas e uma contra-faca, 24 martelos móveis, 2 mancais de $80 \mathrm{~mm}$, 2 rolamentos e uma polia, associada a um motor de baixa rotação (JUMIL, 2014).

Muitas cidades brasileiras já comercializam essas máquinas, em São Luís-Ma, uma trituradora de casca, patenteada (INPI, 2002) e hoje de domínio público, é encontrada facilmente, embora de custo elevado. Trata-se de uma máquina elétrica com 3 navalhas ajustáveis, para obter maior ou menor fragmentação do material fibroso. É capaz de processar até 1800 cascas de coco por hora, incluindo seu pedúnculo.

Tendo em vista a maior dificuldade, decorrente da grande umidade remanescente, a tecnologia de processamento da casca de coco ainda demanda pesquisas, para se obter equipamentos que permitam obter um material de qualidade e baixo custo. Por isso a Embrapa Agroindústria Tropical, em parceria com a indústria Fortalmag, desenvolveu um conjunto de maquinário triturador cuja estimativa de produção está em torno de 250 toneladas de fibras ao ano a partir de aproximadamente 5.500 toneladas de cascas de coco-verde (MATTOS et al., 2014). O que pode fomentar nos empresários e na sociedade em geral a busca por alternativas para o reaproveitamento desse resíduo potencial.

Muitas possibilidades estão sendo descortinadas visando um melhor aproveitamento das cascas de coco na melhoria de algumas propriedades dos solo, principalmente em cidades praianas. Como exemplo cita-se São Luís-Ma, cujas praias mais freqüentadas tem uma extensão de $12 \mathrm{~km}$; produzindo cerca de 7 toneladas de lixo/dia. Desse total, $65 \%$ em volume e $80 \%$ em peso são restos de cocos, descartados pela população após consumo de sua água e de seu albúmen (SANTIAGOet al., 2012).

Silva e França (2013) avaliaram a incorporação da fibra de coco juntamente com esterco de galinha na produção de alface em comunidades rurais. Os pesquisadores verificaram que todos os tratamentos apresentaram desenvolvimento superior ao da testemunha (solo sem fibra). Outra informação foi perceber uma maior capacidade de retenção de água observada nos solos incorporados com a fibra. Esse comportamento é de extrema importância principalmente no ambiente rural da cidade, que apresenta predominância de solos arenosos. Lembrando que a utilização da fibra na horticultura dependerá dos tratamentos dispensados ao material, quais sejam: tempo de estabilização do produto, número de lavagens realizadas, conteúdo de sais solúveis indesejáveis, enriquecimento com fertilizantes, adição de outros componentes para aumentar ou diminuir a aeração e retenção de água, dentre outros.

Segundo Miranda et al., (2004), a utilização da fibra de coco como cobertura morta também apresenta vantagens potenciais, principalmente em solos arenosos que recebem muita radiação solar, como o caso de São Luís. Além de diminuir a incidência do sol, mantendo a temperatura, melhora a reciclagem de nutrientes, redução das perdas de água por evaporação da superfície do solo e manutenção 
de níveis de umidade e temperatura, nas camadas superficiais do solo, adequados ao desenvolvimento de raízes e de microrganismos benéficos para as culturas.

Souza e Jasmim (2004) utilizaram as fibras como suporte para Singônio, uma planta ornamental muito cultivada em vasos. Os melhores resultados para as características morfológicas foram observados naquelas cultivadas com fibras de coco e um substrato comercial, demonstrando o fornecimento de nutrientes ao longo do período de produção (150 dias). Cabendo ressaltar que esses teores, em especial sódio e cloro, devem ser monitorados pois variaram em função da origem e condições de coleta do mesocarpo.

Ramos et al. (2012) estudaram o efeito da utilização de solução nutritiva com substratos a base de fibra e pó da casca de coco na produção de mudas de melancia. O resultado mais promissor foi aquele composto por pó de coco, relacionando este fato à maior retenção de umidade e maior teor de nutrientes nesse substrato, que contribui para melhor desenvolvimento das plântulas.

De acordo com Rosa et al. (2001), o pó de casca de coco misturado com húmus de minhoca em presença de solução nutritiva, foi eficaz na produção de mudas de alface. Já o pó in natura pode ser usado como substrato agrícola, basicamente para produção de mudas; obtendo-se cerca de $1 \mathrm{~kg}$ de pó para cada $2 \mathrm{~kg}$ de fibra processada.

Correia et al. (2003), avaliou o uso de pó de coco verde e maduro na formulação de substratos para formação de mudas de cajueiro anão precoce. O pó de ambas as cascas mostraram-se favoráveis ao desenvolvimento das plantas, apresentando boas características como facilidade de retirada da muda do tubete e agregação das raízes ao substrato, podendo assim, substituir o uso do solo hidromórfico, na proporção de $20 \%$. Desta forma, este substrato revelou-se adequado constituindo uma possibilidade de uso adequado do pó de coco como carga para solos alagados.

Substratos de pó da casca de coco, puro e em combinação com outros materiais (Plantimax e húmus de minhocas) foram testados para produção de mudas de tomateiro. Apesar da excelente emergência das sementes no substrato de pó de coco, estas não apresentaram desenvolvimento tão bom quando combinado com os outros materiais. Em contra partida tiveram uma redução nos custos de 47\% em relação ao Plantmax (SILVEIRA et al., 2002), o que indica ganhos econômicos e, portanto, uma alternativa para a agricultura familiar.

\section{CONSIDERAÇÕES FINAIS}

O levantamento bibliográfico revelou diversos trabalhos de pesquisa sobre o reaproveitamento da casca de coco, que é comumente descartado nas cidades como sendo lixo. As vantagens de se utilizar desse resíduo, seja na indústria ou na agricultura, é que além do contexto econômico e ambiental: aproveitando o resíduo, substituindo produtos sintéticos caros e poluidores por produtos naturais, diminuindo a quantidade de lixo acumulado e evitando a intensa reprodução de vetores transmissores de doenças, tem o contexto social: gerando trabalho e renda para populações. Com essa integração plural no reaproveitamento da casca de coco, descartado em grandes quantidades cotidianamente; pode-se atingir a sonhada sustentabilidade

O mais comum aproveitamento da casca de coco é, sem dúvidas na fabricação de utensílios, desde artesanatos até matéria-prima de produtos industriais. Mas recentemente um aproveitamento vem ganhando destaque: seu re-uso como insumo agrícola. Embora análises laboratoriais desse resíduo (casca de coco) tenham observado alguns impedimentos para ser incorporado em solos, devido sua salinidade, presença de taninos e dificuldade na sua degradabilidade. Ainda assim, essas mesmas análises revelam outras informações que inferem ser um bom no uso como condicionador no manejo de solos.

Estudos com a casca do coco (mesocarpo) na forma de fibra ou de pó mostraram que esse resíduo é adequado, juntamente com outros substratos, para ser incorporado aos solos com alguma deficiências agronômica como por exemplo aqueles de baixa fertilidade natural ou com restrição ao enraizamento, no caso de solos hidromórficos. Esses resultados exitosos podem incentivar nos empresários uma aplicação prática desses resultados, e nos pesquisadores uma buscas de novas formas para o re-uso da casca de coco. Além de fomentar na sociedade a real necessidade do reaproveitamento desse resíduo, que é visto como lixo em diversas cidades brasileiras, principalmente aquelas praianas. 


\section{REFERÊNCIAS}

ABIR. Associação das indústrias de refrigerantes e de bebidas não alcoólicas. Rio de Janeiro. Disponível em: <http://www.abir.org.br/>. Acesso em: 4 março 2014.

ARAGÃO, W. M. Coco: Pós-colheita. Série Frutas do Brasil. EMBRAPA: Brasília, 2002.

APAOLAZA, L. H.; GASCÓ, A. M.; GUERRERO, F. Reuse of waste materials as growing media for ornamental plants. Bioresource Technology. v. 96, p. 125-131, 2005.

BARBOSA, V. Até quando Brasil vai enterrar seu lixo em buracos ilegais? Revista Exame. São Paulo, agosto 2014.

BRIGIDA, A. I. S.; CLAPSON, N. M.; TRIPPER, P. G. et al. Effect of chemical treatments on properties of green coconut fiber. Carbohydrate Polymers, v. 79, p. 832-838, 2010.

CARVALHO J. M. C.; MAIA G. A.; SOUZA P. H. M. et al. Água-de-coco: Propriedades nutricionais, funcionais e processamento. Semina, Londrina, v. 27, n. 3, 437-452, 2006.

CARRIJO, O. A.; LIZ, R. S.; MAKISHIMA, N. Fibra da casca de coco verde como substrato agrícola. Hortic. Bras. V. 20, n.4, 533-535. 2002.

CINTRA, F. L. D.; FONTES, H. R.; PASSOS, E. E. M. et al. (Ed.). Fundamentos tecnológicos para a revitalização das áreas cultivadas com coqueiro gigante no nordeste do Brasil. Aracaju: Embrapa Tabuleiros Costeiros, 2009. 232 p. p. $37-60$

CORRADINI, E.; ROSA, M. F.; MACEDO, B. P. et al. Composição química, propriedades mecânicas e térmicas da fibra de frutos de cultivares de coco verde. Rev. Bras. Frutic., v. 31, n. 3, p.837-846, 2009

CORREIA, D.; ROSA, M. F.; NORÕES, E. R. V.; ARAÚJO, F. B. Uso do pó da casca de coco na formulação de substratos para formação de mudas enxertadas de cajueiro anão precoce. Rev. Bras. Frutic. v. 25, n. 3, p. $557-558,2003$.

CUNHA, L. Pepsico tenta aumentar o consumo de água de coco. Jornal Valor Econômico, São Paulo, p.8, 11 jan. Caderno: Empresas. 2011.

FAO. Food Agriculture Organization. World production of the natural foods. Disponível em: <www.faostat. org/family-farming-2014/pt/>. Acesso em: 10 março. 2014.

FLORENTINO, W. M.; BRANDÃO, A.; MILEO, P. C. et al. Biocompósitos de Poliuretano reforçados com Fibras de Coco Verde. Cadernos Unifoa. 17:11-16. 2011.

INPI. Instituto Nacional de Propriedade Industrial. Patente PI 5184-5(22). Revista da propriedade industrial. Número. 1639. 2002.

HOLANDA, J. S.; FERREIRA NETO, M.; SILVA, R. A. et al. Tecnologia para a produção intensiva de coco Anão verde. Boletim de Pesquisa 34. EMPARN, 2007. 40 p.

JUMIL. Empresa brasileira de implementos agrícolas: grandes, médios e pequenos portes. Disponível em: <http://www.jumil.com.br/>. Acesso em: 10 março 2014.

MARTINS, C. R.; JESUS Jr. L. A. Evolução da produção de coco no Brasil e o comércio internacional. Documentos 164. Embrapa Tabuleiros Costeiros, Aracaju. 2011 
MARTINS, A. P. WATANABE, T. SILVA, P. L. R. et al. Aproveitamento de fibra de coco verde para aplicabilidade têxtil. Revista Redige. 4(2):1-16, 2013.

MATHAI. P. M. Bast and other plant fibers. The Textile Institute. Cambridge: Woodhead Publishing Limited, 2005. p. $275-313$

MATIAS, G. C. S.; COMETTI, N. N.; GÓMEZ, G. P.; ROCHA, J. D. S. Avaliação de substratos comerciais para a produção de mudas de alface. FertBio. Santa Maria, 2007.

MATTOS, A. L. A.; ROSA, M. F.; CRISÓSTOMO, L. A. et al. Beneficiamento da casca de coco verde. Disponível em: <http://www.ceinfo.cnpat.embrapa.br/arquivos/artigo_3830.pdf/>. Acesso em: 10 março 2014.

MIRANDA, F. R.; OLIVEIRA, F. N. S.; ROSA, M. F. Efeito da cobertura morta com a fibra da casca de coco sobre a temperatura do solo. Revista Ciência Agronômica, v. 35, n. 2, p. 335-339. 2004.

RAMOS A. R. P; DIAS R. C. S; ARAGÃO C. A. et al., Mudas de melancia produzidas com substrato à base de pó de coco e soluções nutritivas. Horticultura Brasileira. 30: 339-344. 2012.

REBELLO, F. K.; REALE FILHO, H. B.; FIGUEIREDO, R. N. C. Diagnóstico e perspectiva econômica da cadeia produtiva do coco-da-baía no estado do Pará. Belém: Relatório BASA, 2000. 87p.

REDDY, N.; YANG, Y. Biofibers from agricultural byproducts for industrial applications. Trends in Biotechnology. 23(1):22-27. 2005.

ROSA, M. F.; BEZERRA, F. C.; CORREIA, D. et al. Utilização da casca de coco como substrato agrícola. EMBRAPA, Série Documentos 52. Fortaleza, 2002.

ROSA, M. F.; SANTOS, S. J. S.; MONTENEGRO, A. T. et al. Caracterização do pó da casca de coco verde usado como substrato agrícola. EMBRAPA, Comunicado Técnico 54. Fortaleza, 2001.

SAMAJA J. A reprodução social e a saúde. Casa da Qualidade Editora. Salvador, 2000. 103p.

SANTIAGO, P. D. M.; ROCHA Jr. C. R.; COELHO, L. R. O et al. Caracterizaçao dos resíduos sólidos na praia do Calhau em São Luís, Ma. Anais do Congresso Norte Nordeste de Pesquisa e Inovação, Palmas, 2012.

SANTIAGO, B. H.; SEVAN, C. V. P. Tratamento superficial da fibra do coco: estudo de caso baseado numa alternativa econômica para fabricação de materiais compósitos. Rev. Analitycal. 26(1):42-45.2007.

SATIRO, J. R.; BARROS, P. H. S.; BRANDAO, M. C. et al. Estudo potencial da casca de coco verde para obtenção de etanol lignocelulósico. Anais do Congresso Norte Nordeste de Pesquisa e Inovação, Palmas, 2012.

SANTOS, A. M. Estudo de compósitos híbridos polipropileno,fibras de vidro e coco para aplicações em engenharia. Dissertação (Mestrado) UFPR. Curitiba, 2006. 90p.

SENHORAS, E. M. Oportunidades da Cadeia Agroindustrial do Coco Verde: do coco verde nada se perde, tudo se desfruta. Revista Urutágua, Maringá, n.5, p.08-11, 2004.

SILVA, A. C.; FRANÇA, N. R. Mesocarpo de coco verde utilizado na produção da alface. Reget. 17, 32403245. 2013.

SILVEIRA, E. B.; RODRIGUES, V. J. L. B.; GOMES, A. M. A. et al., Pó de coco como substrato para produção de mudas de tomateiro. Horticultura Brasileira. v. 20, n. 2, p. 211-216, 2002.

SOUZA, N.A.; JASMIM, J. Crescimento de singônio com diferentes tutores e substratos à base de mesocarpo 
de coco. Horticultura Brasileira. v.22, n.1, p.39-44, 2004.

VAN DAM, J.E.G.; VAN DEN OEVER, M.J.A.; KEIJSERS, E.R.P. Production process for high density high performance binderless boards from whole coconut husk. Industrial crops and products.v.20, p.97-101, 2004. 